\title{
Some characteristics of personal interaction in groups and their effects on performance
}

\author{
D. Nel \\ Department of Business Science, University of Cape Town, Rondebosch 7700 Republic of South Africa \\ L.F. Pitt* \\ Graduate School of Business, University of Cape Town, Rondebosch, 7700 Republic of South Africa
}

\begin{abstract}
The authors report the results of an experimental study on the relationship between five group process variables as an evaluation of the personal interaction between group members playing a computerized business decision game. Specific objectives of the study were to examine the experimental data set to determine if it was of a similar structure of the Green \& Taber (1980) instrument, and to assess the impact of five process variables on the outcome, or 'success', of the group interaction process, as measured by profit achieved in the business decision game. The results of the study indicate that there seem to be opportunities for negative socio-emotional behaviours such as rejecting others' positions, arguing, and criticizing in a simulated decision-making environment.
\end{abstract}

Die outeurs rapporteer die resultate van 'n eksperimentele studie oor die verwantskap tussen vyf groepprosesveranderlikes as 'n evaluasie van die persoonlike interaksie tussen groeplede wat 'n gerekenariseerde simulasiespel speel. Die doelwitte van die studie was om te bepaal of die eksperimentele datastel dieselfde struktuur aanneem as die Green \& Taber (1980)-instrument en om die impak van die vyf groepprosesverandelikes op 'sukses' van die groepinteraksieproses te meet, soos bepaal deur die wins behaal in die simulasiespel. Die resultate van die studie dui daarop dat daar geleenthede bestaan vir negatiewe sosioemosionele gedrag soos die verwerping van andere se standpunte, twisgesprek en kritisering in 'n gesimuleerde besluitnemingsomgewing.

* To whom correspondence should be addressed

\section{Introduction}

Group decision-making has been considered a social process which takes individual preferences and combines them into a single group preference. Davis (1969) termed the group process used to combine individual preferences a social decision scheme. Considerable research has been conducted into social decision schemes, describing how the schemes combine individual preferences. The major social decision schemes studied in prior research have been the majority vote, consensus (Tjosvold \& Field, 1983) and nominal vote analog techniques (Van de Ven \& Delbecq, 1971; Delbecq, Van de Ven \& Gustafson, 1975). In a major study on group approaches for improving decision making, Schweiger, Sandberg \& Ragan (1986) considered dialectical inquiry, devil's advocacy, and consensus as social decision schemes. Mitroff \& Emshoff (1979) also examined a dialectical approach in a study on strategic assumption making. Others have tested the effects of judgmental schemes (Stumpf, Freedman \& Zand, 1979; Stumpf, Zand \& Freedman, 1979).

Little research, however, has been done regarding the impact of social decision schemes upon group process variables. Hackman \& Morris (1975) pointed to many input variables which affect group processes that are not readily controlled or managed by the group members. Green \& Taber (1980) were of the opinion that research should concentrate on variables which can be controlled, and emphasized two reasons for further research into the relationship between social decision schemes and group processes. Firstly, social decision schemes are controllable - therefore research should focus on variables which can be controlled and which have important implications for the group decision-making process. Secondly, in organizations the quality of the decision process is sometimes as important as the quality of the solution. According to Green \& Taber (1980), if social decisions schemes do affect the group process, and if the quality of the decision process is important to the leader, an understanding of the relationship between various formal schemes and group process variables is necessary. In an experimental study, Green \& Taber (1980) compared the effects of three group decisionmaking schemes, a nominal voting scheme, a consensus scheme, and a majority vote scheme with respect to their effects on the degree of conformity of individuals to the group decision; on member satisfaction with the decision and the group decision scheme; and, on the amount of participation, informal leadership, and negative socioemotional behaviour induced within the group during decision making.

\section{Green \& Taber's measures of the group decision process}

Green \& Taber (1980) developed their instrument for measuring personal interaction behaviour from the Bales (1950) categories. Bales constructed a system of interaction process analysis (IPA) that combined both a structured set of categories for observation and a set of theoretical concepts underlying those categories. The basic theoretical notions underlying IPA are instrumental or task-oriented concerns associated with the effort to deal with the group's task, and expressive or socio-emotional concerns associated with the 
interrelationships of the group members. Both instrumental and expressive concerns operate continually. A particular group will give emphasis to one over the other at various times during group discussion. The Bales IPA theoretical conformation asserts that there is an orderly series of phases involved in the instrumental activities of the problem-solving group, and a parallel cycle of phases of expressive behaviour. The instrumental phases focus firstly on orientation, which implies the gathering of information, then on evaluation of that information, and finally on control and decision making. Such instrumental activities will produce strains in the social-emotional aspects of the group. These strains increase as the task phases continue, but efforts to counter these social-emotional strains also increase.

Based on interaction process analysis, Green \& Taber (1980) constructed a self-report scale which provides five calibrations of group process: personal task participation, negative socio-emotional behaviour, solution satisfaction, decision scheme satisfaction, and informal leadership. These five benchmarks each consist of a number of items to form a composite index which defines each measure. Personal task participation consists of the following five items: (X1) making suggestions about doing the task; (X2) giving information about the problem; (X3) asking others for their thoughts or opinions; (X4) showing attention and interest in group activities; and (X5) asking suggestions from others in the group. The second measure, negative socio-emotional behaviour, also comprises five items, namely: (X6) feeling frustrated or tense about other's behaviour; (X7) rejecting other's opinions or suggestions; (X8) expressing negative opinions about someone's behaviour; (X9) own opinions or suggestions being rejected; and (X10) expressing a negative opinion about own behaviour. The five items under the third measure - solution satisfaction - relate to: (X11) satisfaction or dissatisfaction with the quality of the group solution; (X12) whether the final solution reflects group input; (X13) commitment to the group solution; (X14) confidence in the correctness of the group solution; and (X15) personal responsibility for the correctness of the group solution. The fourth measure, decision scheme satisfaction, probes the group problemsolving process on five (X16-X20) semantic differential scales. Three items address the construct of informal leadership, namely: (X21) whether a particular member influenced the final solution more than the rest of the group; (X22) if anyone emerged as an informal leader; and (X23) if one or two members strongly influenced the group decision.

These measures therefore deal with the descriptions of an individual's behaviour as well as with the behaviour of others toward a specific person. The items within each measure also probe the evaluative ratings of several specific group processes and outcomes. However, the instrument essentially measures three dimensions of the effects of personal interaction on the outcomes of the group process, namely group member participation (personal task participation and negative socioemotional behaviour), group member satisfaction (solution satisfaction and decision scheme satisfaction), and informal leadership. The Green \& Taber (1980) study revealed that group decision schemes (nominal vote, majority vote, and consensus) did significantly affect the above-mentioned process variables. Watson (1987) hypothesized that solution satisfaction and decision scheme satisfaction would be influenced by different degrees of decision support systems. In other words, groups assisted by structure, compared to freely interacting groups would produce decisions that groups would perceive to be of high solution satisfaction and decision scheme satisfaction, and that the presence of structure improves the outcome of the group interaction process, which directly leads to an improvement in group member satisfaction. The major objective in the study discussed in this paper was to measure the outcome of the group interaction process in a computerized decision simulation game, as defined by Green \& Taber's five process variables.

\section{Objectives and Methodology}

This paper reports on the relationship between the five process variables as an evaluation of personal interaction between group members (Green \& Taber, 1980) playing the computerized business decision game, The Marketing Game (Mason \& Perreault, 1987). The sample consisted of 95 undergraduate students divided into 24 groups who played the game over a period of nine weeks, making nine sets of decisions. Following the procedures used by Glazer, Steckel \& Winer (1987), students were responsible for forming their own groups, and most students had previously worked with the other members of their team. At the end of the game each student was required to complete the instrument developed by Green \& Taber (1980), which is shown in Appendix A.

More specific objectives of the study were, firstly, to examine the experimental data set to determine if it was of a similar structure to the process variables of the Green \& Taber (1980) instrument; and, secondly, to assess the impact of the five process variables on the outcome, or 'success' of the group interaction process, as measured by the profit achieved in the business decision game.

The nature of the instrument requires that the first two measures be rated on a five-point agree-disagree Likerttype scale. Respondents were required to indicate a degree of agreement or disagreement with a set of five items on each of the first two measures. On the third measure - solution satisfaction - respondents rated items on a five-point semantic differential scale. The informal leadership measure is rated on a 'yes' $=1$ to 'no' $=5$ scale.

\section{Results and Discussion}

The scoring of the instrument followed the method established by Green \& Taber (1980), where each process variable is a composite index. Scoring involves a five-step rating procedure in the range of $1-5$ on each item within each process variable. A process variable 
such as solution satisfaction would for example, produce a score in the range of $5-25$ where a high score corresponds to high solution satisfaction. The other process variables are scored in the same manner. Green \& Taber's instrument has not been subjected to extensive validity or reliability testing, but it provides an instrument that is considered superior to those used in previous research because it uses multiple self-report items for each measure (Watson, 1987).

\section{Reliability and validity of the experimental data}

To address the issues of reliability and validity, Green \& Taber (1980) have demonstrated that their questionnaire repeatedly measures five factors, which they label as personal task participation, negative socio-emotional behaviour, solution satisfaction, decision scheme satisfaction, and informal leadership. Any data set collected by means of the Green \& Taber (1980) instrument should therefore evince a similar structure. In addition, the items on each composite index should compare adequately with those suggested by Green \& Taber (1980). Thus, before an attempt could be made to establish a relationship between the process variables and the success of the interaction process (as measured by profit) could be attempted, the experimental data collected for this study was factor analysed. Following the approaches of Green \& Taber (1980) and Watson (1987) a varimax rotated factor analysis revealed five factors with eigenvalues exceeding the customary cut-off point of one. The five factors extracted are presented in Table 1 with the varimax factor loadings for each item defining an index. As shown in Table 1 the items describing the factors follow a similar pattern to that found by Green \& Taber (1980). The items describing the factor (process variable) decision scheme satisfaction are the same as those found by Green \& Taber (1980). This finding is also reported by Watson (1987) suggesting decision scheme satisfaction to be a very reliable and valid process variable. The factor solution satisfaction, concurs on three of the five items suggested by Green \& Taber (1980). The other two solution satisfaction items load onto the decision scheme satisfaction factor. This is not an unexpected finding since both of these process variables measure the same dimension, namely group member satisfaction (Green \& Taber, 1980; Watson, 1987). Factor 3 signals clear identification of the items describing informal leadership and are the same as found by Green \& Taber (1980). This seems to indicate informal leadership to be a reliable and valid process variable. In turn factor 4 , negative socio-emotional behaviour, concurs on four of the five items found by Green \& Taber (1980). Factor 5, personal task participation, agrees with two of the five items, while the other three items load onto the solution satisfaction factor. Any attempt at clarification of this would be mere speculation - it could be that item 1 (made suggestion about doing the task), item 2 (gave information about the problem), and item 4 (showed attention and interest in the group's activities) are not associated with personal task participation because the group members in this study had been required to write a test on the business game before being allowed to participate, to ensure a minimum knowledge level of the principles, before being allowed to play. In other words there was no need to discuss the nature of the group task, or gain information about the problem, but rather a need to reach a satisfactory solution. This could perhaps explain why these items loaded onto, factor 2, solution satisfaction. With this reasonable close concurrence of the structure of the experimental data with that of the Green \& Taber (1980) instrument, it can be assumed that the two sets of data follow a comparable pattern. A similar framework was found by Watson (1987) which lead him to conclude that the Green \& Taber (1980) instrument is reliable and valid. For this reason the next step in the analysis was executed, namely an attempt at establishing a relationship between"the Green \& Taber (1980) process variables and the success of the interaction process, as measured by profit in the business game.

Table 1 Varimax factor loadings of experimental data set factors

\begin{tabular}{|c|c|c|c|c|c|}
\hline \multirow[b]{2}{*}{ Item } & \multicolumn{5}{|c|}{ Factors } \\
\hline & $\begin{array}{c}1 \\
\text { DSS }\end{array}$ & $\begin{array}{c}2 \\
\text { SS }\end{array}$ & $\begin{array}{r}3 \\
\mathrm{IL}\end{array}$ & $\begin{array}{c}4 \\
\text { NSB }\end{array}$ & $\begin{array}{c}5 \\
\text { PTP }\end{array}$ \\
\hline $\mathrm{X} 1$ & 0,1454 & 0,6724 & 0,2030 & 0,2222 & $-0,1186$ \\
\hline $\mathrm{X} 2$ & 0,01149 & 0,8568 & $-0,0158$ & 0,3451 & 0,0488 \\
\hline $\mathrm{X} 3$ & $-0,1047$ & $-0,0232$ & $-0,0798$ & $-0,0109$ & 0,8766 \\
\hline $\mathrm{X} 4$ & 0,0397 & 0,6364 & $-0,2360$ & $-0,2206$ & 0,2308 \\
\hline$\times 5$ & $-0,0893$ & $-0,0115$ & $-0,0778$ & 0,0666 & 0,8908 \\
\hline $\mathrm{X} 6$ & 0,5746 & 0,0381 & 0,4011 & 0,4316 & $-0,0425$ \\
\hline $\mathrm{X7}$ & 0,3018 & 0,1911 & $-9,41 E-3$ & 0,7097 & $-0,2599$ \\
\hline $\mathrm{X} 8$ & 0,4281 & 0,2153 & 0,4521 & 0,4761 & -0,0937 \\
\hline $\mathrm{X} 9$ & 0,2805 & $-0,2939$ & $-0,1739$ & 0,5793 & 0,1377 \\
\hline $\mathrm{X} 10$ & 0,0516 & $-0,1527$ & 0,2486 & 0,5934 & 0,2556 \\
\hline $\mathrm{X} 11$ & $-0,7927$ & $-0,0843$ & $-0,0932$ & $-0,2003$ & $-0,0483$ \\
\hline $\mathrm{X} 12$ & $-0,2323$ & 0,6448 & 0,1366 & $-0,0953$ & $-0,3219$ \\
\hline $\mathrm{X} 13$ & $-0,1274$ & 0,7281 & $-0,0394$ & $-0,3278$ & $-0,0919$ \\
\hline $\mathrm{X} 14$ & $-0,6625$ & 0,3447 & $-0,0383$ & $-0,1720$ & $6,6 \mathrm{E}-3$ \\
\hline $\mathrm{X} 15$ & $-0,0697$ & 0,7926 & 0,2048 & 0,1041 & 0,0556 \\
\hline $\mathrm{X} 16$ & 0,8590 & $-0,0801$ & 0,2221 & 0,1002 & 0,0235 \\
\hline $\mathrm{X} 17$ & 0,7797 & $-0,0918$ & 0,2660 & 0,1166 & $-0,1147$ \\
\hline $\mathrm{X} 18$ & 0,7181 & $-0,1694$ & 0,1871 & 0,2287 & $-0,2590$ \\
\hline $\mathrm{X} 19$ & 0,8177 & $-2,96 \mathrm{E}-4$ & 0,0509 & $9,42 \mathrm{E}-3$ & $-0,0438$ \\
\hline $\mathrm{X} 20$ & 0,9003 & $-0,0123$ & 0,1104 & 0,0479 & $-0,0271$ \\
\hline $\mathrm{X} 21$ & $-0,3979$ & $-0,0123$ & $-0,7171$ & $-0,1261$ & 0,0950 \\
\hline $\mathrm{X} 22$ & $-0,0774$ & $-0,1475$ & $-0,7922$ & 0,1160 & 0,0138 \\
\hline $\mathrm{X} 23$ & 0,3411 & 0,0146 & 0.6969 & 0,1743 & $-0,1224$ \\
\hline
\end{tabular}

$\mathrm{X} 1-\mathrm{X} 23$ is the items forming the composite indexes as discussed in the text.

DSS - Decision scheme satisfaction; SS - solution satisfaction; IL informal leadership; NSB - negative socio-emotional behaviour; PTP - personal task participation 
The relationship between the process variables and profit

The null hypothesis is that there is no relationship between the effects of personal interaction as measured by the five Green \& Taber (1980) process variables and the success of the interaction process, as measured by profit achieved by the group in the computerized decision simulation.

A comparison of the overall scores for each of the process variables is presented in Table 2 .

To test the null hypothesis a multiple regression analysis with profit as the criterion variable and the process variable scores in Table 2 as predictor variables was carried out in attempt to establish a relationship. As shown in Table 3, solution satisfaction shows a significant $t$ value ( $t=5,4463 ; p>0,0000)$, with informal leadership being very close to approaching significance. From the ANOVA for the full regression in Table 3 it is apparent that the 95 observations yield a significant regression, with an $F$ ratio of $1,1938 \mathrm{E} 0001$. The multiple coefficient of determination, $R^{2}$ is 0,401445 , which suggests that the fitted model explains around $40 \%$ of the total variance in profit. The adjusted $R^{2}$ is 0,367819 . The latter statistic adjusts for the number of independent variables in the regression. The standard error of the estimate is 5755,49 , and measures the unexplained variability in the dependent variable. A further observation is that negative socio-emotional behaviour which has a non-significant $t$ value contributes, in addition to solution satisfaction, significantly to the fit at the time of entering the regression.

A conclusion to be reached from the regression analysis is that negative socio-emotional behaviour and solution satisfaction are positively related to profit in a business game. Therefore, there seem to be opportunities for negative socio-emotional behaviours such as rejecting others' positions, arguing, and criticizing in a simulated decision-making environment. The hypothesis is therefore rejected - in other words there is a significant relationship between personal interaction in groups and success in a business game as measured by profit.

This result is consistent with the Bales (1950) interaction process analysis theory, namely, that

Table 2 Summary statistics of the Green \& Taber process variables $(n=95)$

\begin{tabular}{lrrrrc}
\hline Process variable & Mean & $S D$ & High & Low & Median \\
\hline X1 & 19,21 & 2,38 & 25 & 11 & 20 \\
X2 & 10,63 & 3,76 & 22 & 5 & 10 \\
X3 & 19,21 & 2,89 & 25 & 11 & 19 \\
X4 & 10,75 & 3,84 & 24 & 5 & 10 \\
X5 & 8,37 & 1,61 & 13 & 5 & 8 \\
\hline
\end{tabular}

$\mathrm{X} 1$ = Personal task participation; $\mathrm{X} 2$ = negative socio-emotional behaviour; $\mathrm{X} 3=$ solution satisfaction; $\mathrm{X} 4=$ decision scheme satisfaction; and $\mathrm{X} 5$ = informal leadership
Table 3 Process variables related to profit: estimated regression coefficients, $t$ test values and coefficient of multiple determination $\left(R^{2}\right)$

\begin{tabular}{lcccc}
\hline Variable & Coefficient & Std. Error & $t$ value & Prob $(>t)$ \\
\hline Constant & $-1,462975 E 4$ & 8710,493278 & $-1,6796$ & 0,0966 \\
X1 & $-391,205874$ & 275,488795 & $-1,4200$ & 0,1591 \\
X2 & $-225,239118$ & 201,928214 & $-1,1154$ & 0,2677 \\
X3 & 1532,49577 & 281,384649 & 5,4463 & 0,0000 \\
X4 & 12,426186 & 226,717708 & 0,0548 & 0,9564 \\
X5 & 722,034228 & 391,60172 & 1,8438 & 0,0685 \\
\hline
\end{tabular}

Analysis of variance for the full regression

Source Sum of Squares $D F$ Mean Square $F$ Ratio Prob $(>F)$

Model 1,9773E0009 5 .3,9546E0008 1,1938E0001 7,4929E-009

Error $\quad 2,9482 \mathrm{E} 0009 \quad 89 \quad 3.3126 \mathrm{E} 0007$

$R^{2}=0,4011445$

Adjusted $R^{2}=0,367819$

Standard Error of Estimate $=\mathbf{5 7 5 5 , 4 9}$

Analysis of variance for variables in the order fitted

\begin{tabular}{lccccc}
\hline Source & Sum of Squares & $D F$ & Mean Square & $F$ Ratio & Prob $(>F)$ \\
\hline X1 & $8,4426 \mathrm{E} 0007$ & 1 & $8,443 \mathrm{E} 0007$ & 2,5487 & 0,1139 \\
X2 & $6,4758 \mathrm{E} 0008$ & 1 & $6,476 \mathrm{E} 0008$ & 19,5491 & 0,0000 \\
X3 & $1,1282 \mathrm{E} 0009$ & 1 & $1,128 \mathrm{E} 0009$ & 34,0574 & 0,0000 \\
X4 & $4,5287 \mathrm{E} 0006$ & 1 & $4,529 \mathrm{E} 0006$ & $\mathbf{0 , 1 3 6 7}$ & $\mathbf{0 , 7 1 6 4}$ \\
X5 & $1,1261 \mathrm{E} 0008$ & 1 & $1,126 \mathrm{E} 0008$ & 3,3996 & 0,0685 \\
\hline
\end{tabular}

$\mathrm{X} 1$ = personal task participation; $\mathrm{X} 2$ = negative socio-emotional behaviour; $\mathrm{X} 3=$ solution satisfaction; $\mathrm{X} 4=$ decision scheme satisfaction; $\mathrm{X} 5$ = informal leadership

instrumental activities produce strains in the socioemotional aspects of groups. McGrath (1984) acknowledged this phenomenon and was of the opinion that these strains increase as the group moves through the task phases; but efforts to counter these socioemotional strains also increase. Hence, the increase in both positive and negative aspects of socio-emotional activity as the group progresses through its task activity phases. Since solution satisfaction returned a significant regression it seems that the give-and-take arguments of socio-emotional behaviour contributed to solution satisfaction. Solution satisfaction is an assessment of the group's contentment with its outcome (Watson, 1987). The fact that informal leadership is not significant in the regression is consistent with the findings of the factor analysis in that group members felt they had less personal task participation. It would seem as though there was little opportunity for an informal leader to emerge, since group members demonstrated high socioemotional behaviour which in turn stimulated other group processes such as conformity of members to a group decision, particularly if solution satisfaction is high. Moreover, the insignificance of the decision scheme satisfaction is to be expected since no specific 
decision schemes such as those employed by Green \& Taber (1980) were required by the experimental design. This is perhaps an area for future research. This study could be replicated, but the experimental design should control group approaches to strategic decision making. A comparative analysis of dialectical inquiry, devils advocacy, and consensus decision schemes would provide much needed additional information in this regard.

\section{References}

Bales, R.F. 1950. Interaction process analysis: a method for the study of small groups. Addison-Wesley, Cambridge, MA.

Davis, J.H. 1969. Group performance, Addison-Wesley, New York.

Delbecq, A.L., Van de Ven, A.H. \& Gustafson, D.H. 1975. Group techniques for program planning. Scott Foresman, Glenview, Illinois.

Glazer, R., Steckel J.H. \& Winer, R.S. 1987. Group process and decision performance in a simulated marketing environment. J. Bus. Res., vol.15.

Green, S.G. \& Taber, T.D. 1980. The effects of three social decision schemes on decision group process. Organ. Behav. Human Perform., vol.25.

Hackman, J.R. \& Morris, C.G. 1975. Group tasks, group interaction process and group performance effectiveness: a review and proposed integration. In: Berkowitz, L., (Ed.), Advances in experimental social psychology. Academic Press, New York.

Mason, C. \& Perreault, W.J. 1987. The marketing game, Students Manual, Richard D. Irwin, Homewood, Illinois.

McGrath, J.E. 1984. Groups: interaction and performance. Englewood Cliffs, Prentice-Hall, Inc., New Jersey.

Mitroff, I.I. \& Emshoff, J.R. 1979. On strategic assumption-making: a dialectical approach to policy and planning. Acad. Manage. Rev., vol.4(1)

Schweiger, D.M., Sandberg, W.R. \& Ragan, J.W. 1986. Group approaches for improving strategic decision making: a comparative analysis of dialectical inquiry, devil's advocacy, and consensus. Acad. Manage. J., vol.29(1).

Stumpf, S.A., Freedman, R.D. \& Zand, D.E. 1979. Judgmental decisions: among group membership, group functioning, and the decision situation. Acad. Manage. J., vol.23(4).

Stumpf, S.A., Zand, D.E. \& Freedman, R.D. 1979. Designing groups for judgmental decisions. Acad. Manage. Rev., vol.4(4).

Tjosvold, D. \& Field, R.H.G. 1983. Effects of social context on consensus and majority vote decision making. Acad. Manage. J., vol.26(3).

Van de Ven, A.H. \& Delbecq, A.L. 1971. Nominal versus interacting group processes for committee decision-making effectiveness. Acad. Manage. J., vol.14(3).

Watson, R.T. 1987. A study of group decision support system use in three and four-person groups for a preference allocation decision. Unpublished Ph.D. thesis, University of Minnesota.

Appendix A Group process variables (Green \& Taber, 1980)

Directions: We are interested in how your group approached the task. The questionnaire is composed of 23 statements. Please indicate in the space provided the degree to which each statement applies to you or your group. Indicate your choice by circling the appropriate marker. There are no right or wrong answers. Many of the statements are similar to other statements. Do not be concerned about this. Work quickly, just record your first impression.

Indicate your level of agreement with the following statements:

1. To what extent do you feel personally responsible for the correctness of the group solution?

(1)

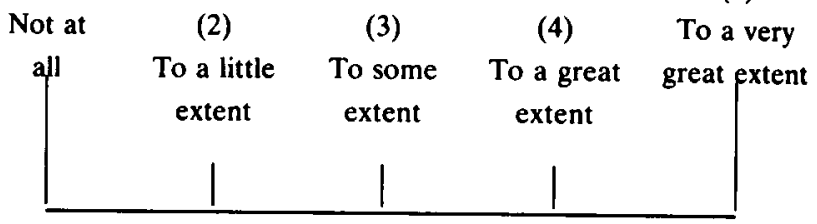

2. Others expressed a negative opinion about your behaviour.

(1)

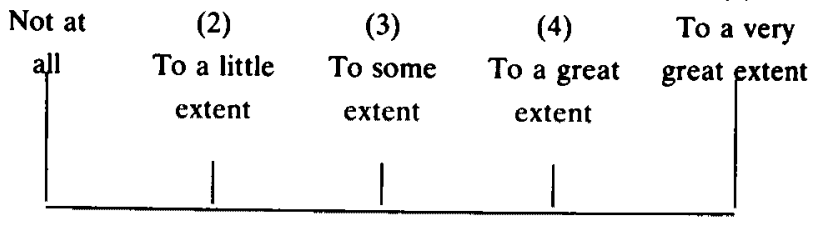

3. To what extent does the final solution reflect your inputs?

(1)

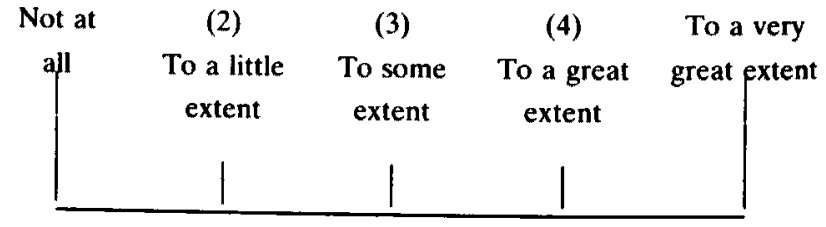

4. I made suggestions about doing the task.

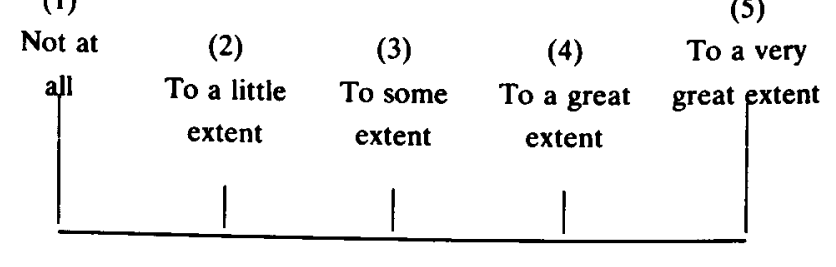

5. I felt frustrated and tense about others' behaviour.

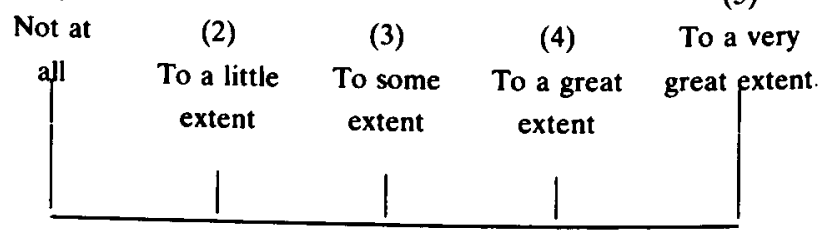


6. To what extent are you confident that the group solution is correct?

(1)

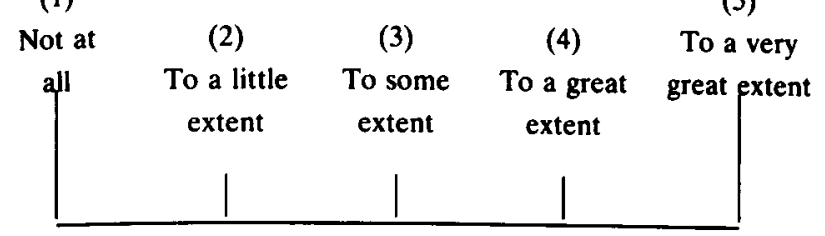

7. Did one or two memebers strongly influence the group decision?

(1)

$$
\text { (2) }
$$

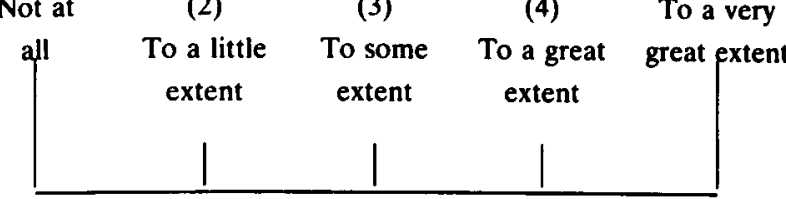

8. To what extent do you feel committed to the group's solution?

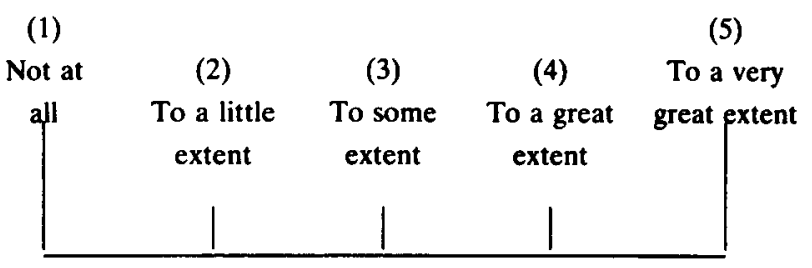

9. I expressed negative opinions about someone's behaviour.
(1)

Not at

10. I rejected other's opinions or suggestions.

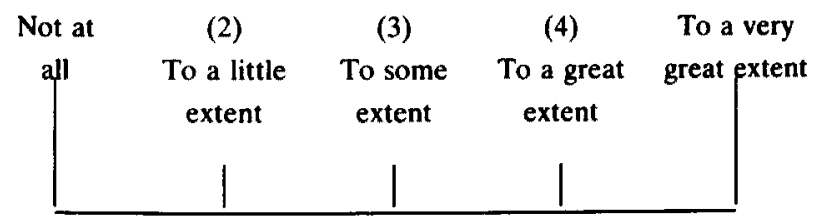

11. I showed attention and interest in the group's activities.

(1)

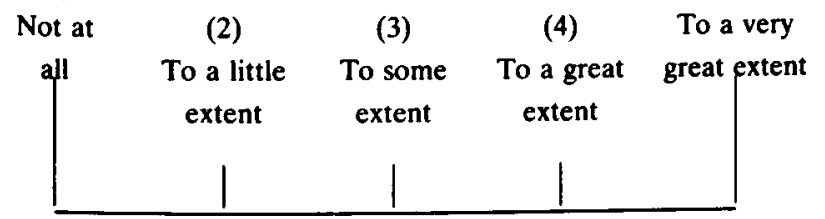

12. Your opinions or suggestions were rejected.

(1)

(5)

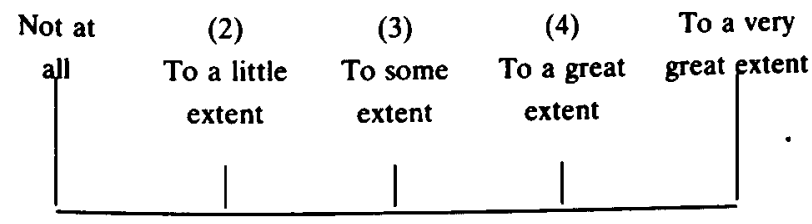

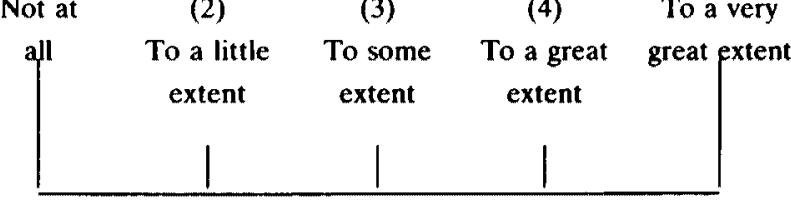

13. I gave information about the problem.
(1)

Not at

all
(2)

To a little

extent
(3)

To some

extent
(5)

(4)

To a very

To a great great extent extent
14. I asked others for their thoughts and opinions.
(1)

Not at

all
(2)

To a little extent

(3)

(4)

(5)
To a very

great extent
15. I asked for suggestions from others in the group.
(1)

Not at

all
(5)

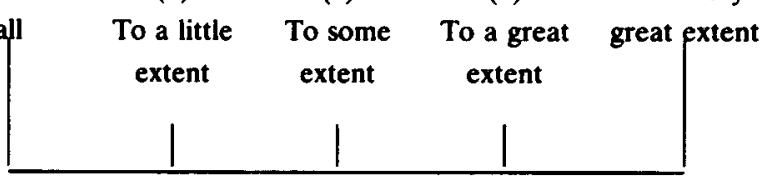

16. How sattisfied or dissatisfied are you with the quality of your group's solution?

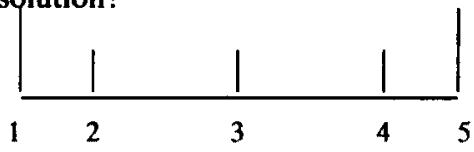

very dissatisfied

very satisfied

17. How would you describe your group's problem solving process?

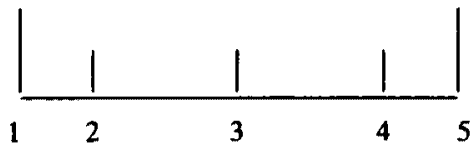

efficient

inefficient

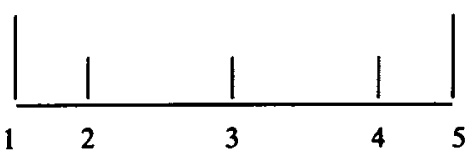

coordinated uncoordinated

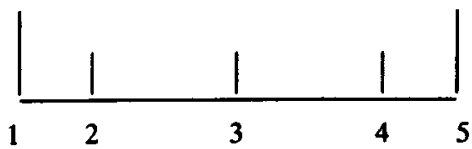

fair

unfair

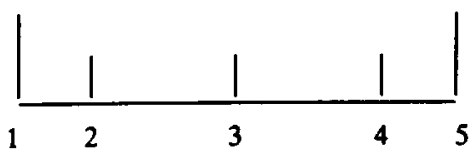

understandable

confusing

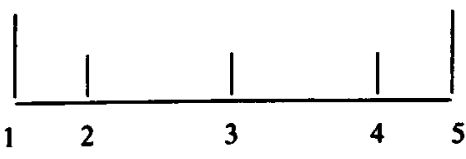

satisfying 
18. Do you feel one person influenced the final solution more than the rest of the group?

Yes

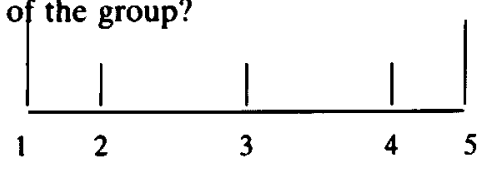

19. Did anyone emerge as an informal leader?

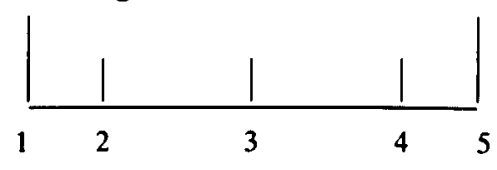

No Yes 